\title{
Effect of parental depression on asthmatic children's problem behavior and academic performance: using actor and partner interdependence model of parental variables
}

Jeong Min Kim

Jinju Health College

Hanna Lee

Changwon National University

jeongwon Han ( $\nabla$ hjw0721@naver.com )

Kyung Hee University

Research article

Keywords: Asthma, Depression, Problem

Posted Date: December 6th, 2019

DOl: https://doi.org/10.21203/rs.2.18031/v1

License: (c) (i) This work is licensed under a Creative Commons Attribution 4.0 International License.

Read Full License 


\section{Abstract}

\section{Background}

The health issues of children with asthma is emerging to be a social problem because in many cases it is a disease that requires repetitive and long-term treatment, and the financial burden of parents raising children with asthma is relatively greater than parents raising normal children. It is necessary for health care providers to approach the mental health of parents in addition to managing the health of asthmatic children so that asthmatic children recover, smoothly adjust to school life like other normal children. This study attempts to determine the factors on the problem behavior and academic performance of the children with asthma.

Methods

The data of 236 pairs of children and parents from the 10th Panel Study on Korean Children were used and analysis was performed using SPSS 20.0 and AMOS 20.0.

Results

Parental depression had actor and partner effects on marital conflict, and marital conflict perceived by the father had actor and partner effects on parent-child interactions, while marital conflict perceived by the mother had actor effect on parent-child interactions. Parent-child interaction perceived by the father was found to affect the problem behavior of children, and parent-child interaction perceived by the mother was seen to affect the problem behavior of children. The problem behavior of children affects academic performance.

\section{Discussion}

This study is significant since it prepares basic data for improving the academic performance of children with asthma. We suggest research that longitudinally confirms the influence using variables presented in this study is necessary.

\section{Background}

Recently, the number of patients complaining of respiratory diseases due to particulate matter has been increasing, and more specifically, dust has been reported to seriously affect the health of asthmatic children [1]. In many cases, asthma begins in early-childhood (43.2\% of asthmatic patients are below the age of 12) and continues to adulthood [2]. The health issues of children with asthma is emerging to be a social problem because in many cases it is a disease that requires repetitive and long-term treatment, and the financial burden of parents raising children with asthma is relatively greater than parents raising normal children [3]. Furthermore, parents of asthmatic children have the greater psychological burden of performing many roles since they experience the disease process and growth of their children at the same time [4]. 
If the parents of asthmatic children experience financial and psychological burdens at the same time, the probability of them experiencing depression increases. Their depression is an important factor connected to the recovery and school life of the children [5]. A previous study of asthmatic children [6] reported that parental depression is related to their use of medical institutions, emergency room visits, hospitalizations, and asthmatic complications. Some studies studies $[7,8]$ have reported that parental depression increases the attitude of parental neglect, resulting in a negative effect on children's recovery. Asthmatic children are highly dependent on parents due to the disease, and since school-going children grow through close interaction with their parents, their experience of an unstable parent-child relationship may cause them to display problem behavior such as depression, anxiety, withdrawal behavior, and sleep disorders [9].

The repeated display of problem behavior of school-going children tends to be sustained and reinforced as children grow, and such children will eventually experience maladjustment to school life and decreased academic competence. In particular, a previous study [10] related to asthmatic children confirmed that family factors are among those that have the greatest influence on children, affecting their adjustment to daily life. Negative emotions of parents negatively influence interaction between parents and children, ultimately causing problem behavior in children [11]. These factors have been found to reduce learning flow and performance of children at school. Eventually, parents' mental health and the relationship between parents and children become crucial factors that affect not only children's health but also their adjustment and performance at $[11,12]$. Accordingly, it is necessary for health care providers to approach the mental health of parents in addition to managing the health of asthmatic children so that asthmatic children recover, smoothly adjust to school life like other normal children, and improve their performance at school.

Depression of parents who raise children with asthma, however, is not just a personal problem but a mental health issue that affects both parents: if one of the parents experiences depression, it will be transferred to the other, causing negative emotions such as marital conflict, which will negatively affect the relationship between parents and children, and the children's social life [5]. Accordingly, research on asthmatic children and parents needs to collect data on parents and children as a unit and make efforts to understand the phenomena by analyzing the data of parents using actor and partner interdependence model. Since married couples are in an interdependent relationship, the Actor-Partner Interdependent Model proposed by Kenny [13] is used to analyze the interrelationships between variables related to parental depression. If couples' data are separately analyzed, interpersonal dynamics between the couple cannot be examined. Even if data were collected from all couples and interdependent data were analyzed by treating them as independent data, it would violate one of the main assumptions of inferential statistics, i.e., data independence, resulting in smaller estimated standard errors and possibly Type I errors. Accordingly, this study attempted to prepare basic data to develop a program for asthmatic children and parents. Using asthmatic children and parents as subjects, the study attempted to determine the relationship between children's problem behavior and performance in school based on actor and partner effects that are outcomes of parental depression, marital conflict, and interaction between children and parents. 


\section{Method}

\section{Subjects}

The subjects of the present study were children and parents who participated in the 10th year (2017) Panel Study on Korean Children (Korea Institute of Child Care and Education, KICCE). The Panel Study on Korean Children that is used in the present study is a longitudinal survey of children born in 2008 , their parents, and community environment. Currently, data up to 10th year (2017) of the Panel Study on Korean Children are released to the general public. The present study used the data of parents who were 19 years or older and their children.

The Panel Study on Korean Children targeted households that gave birth to a newborn baby from April to July 2008 at the sample medical institutions that had 500 or more annual deliveries in 2006 . It excluded households not included in the sample survey and the ones who declined to participate in the survey. Subjects who were excluded from the survey were cases where the mother of a newborn baby was not able to communicate in Korean, the mother's postnatal health was very poor, the newborn or mother had a serious illness, the newborn was expected to be adopted, the mother had given birth to more than one child, and the mother was 18 years or younger. The Panel Study on Korean Children recruited a preliminary sample of 2,562 households of which 2,150 households with a newborn were selected as the final sample. Sampling of the Panel Study on Korean Children employed a stratified multi-stage sampling technique in which birthing medical institutions were selected in the 1 st stage, households who gave birth at the selected medical institutions as a pilot sample in the 2nd stage, and the final sample was drawn from the pilot sample households that were willing to participate in the panel survey in the 3rd stage. The sample maintenance rate presented by the research team of the Panel Study on Korean Children (69\% for the $10^{\text {th }}$ panel survey) was confirmed for the sample validity of the present study. The final subjects for the present study were 236 children who experienced asthma symptoms, 236 fathers, and 236 mothers of the children from among those who participated in both panel survey and health survey.

\section{Measurement}

\section{Depression}

Depression was measured with an abbreviated depression scale (K6) consisting of six items developed by Kessler et al. [14] for the US National Health Interview Survey (NHIS) and used to measure the mental health of the general public. Each item was measured on a 5-point Likert scale: No feeling at all (1 point), not feeling very much ( 2 points), often feeling ( 3 points), almost feeling ( 4 points), always feeling ( 5 points): the higher the score, the higher the level of depression. Depression is classified as normal for the range 6-13 points, mild/moderate for 14-18 points, and severe for 19-30 points. The reliability of the instrument measured by Cronbach's a in the study of Kessler et al. [14] was.89. In the current study, Cronbach's alphas for the fathers' and mothers' instruments were.93 and.92, respectively. 


\section{Marital conflict}

The marital conflict scale was developed by Markman et al. [15] and translated and modified by the research team of the Panel Study on Korean Children and consists of a total of eight items measured on a 5-point scale: strongly disagree (1 point), disagree (2 points), neutral (3 points), agree (4 points), strongly agree (5 points). The reliability of the instrument measured by Cronbach's a was.96 in the study of Markman et al. (2001), and in the current study it was. 91 (father) and.92 (mother).

\section{Parent-child interaction}

For parent-child interaction, the research team of the Panel Study on Korean Children extracted a few items asking about parent-child interactions based on home environment, activities, and cognitive stimulation from the Early Childhood Longitudinal Study-Kindergarten cohort (ECLS-K). The research team of the Panel Study on Korean Children obtained permission to use the instrument from the ECLS research institute and used it as the final measuring instrument after the confirmation of reverse translated content by a third party from the ECLS. The instrument consists of a total of nine items on a 4point scale: never (1 point), once or twice a week (2 points), 3 to 6 times a week (3 points), every day (4 points); items were measured by parents. The higher the sum of the scores, the higher the interaction between parent and child. Cronbach's alphas for father's and mother's instruments in the study were.89 and.82, respectively.

\section{Problem behavior of children}

To measure problem behavior in the survey of the Panel Study on Korean Children, the behavior evaluation scale of the Child Behavior Checklist (CBCL) developed by Kim et al. [16]. For the current study questions related to internalizing and externalizing problems were extracted and used. Internalizing problems refer to internalized and overly controlled behavior, such as passive and withdrawn behavior, emotional insecurity, and physical symptoms, and externalizing problems refer to attention problems, less controlled behavior such as aggressive behavior. The instrument consists of a total of 100 items measured on a 3-point scale: never ( 0 point), sometimes ( 1 point), often ( 2 points): these items are measured by the child. The higher the score, the higher the level of problem behavior. The reliability of the instrument measured by Cronbach's a was.77-.86 in the study of Kim et al. [16], and the reliability of the instrument in the study was.80-.82.

\section{Academic performance of children}

The academic performance of children refers to the results of a longitudinal effect study of comprehensive childcare services of Samsung Childcare Center by Rhee et al. [17], which supported and presented by the research team of the Panel Study on Korean Children. Academic performance scale is composed of a total of 10 items (5-point scale: not yet ( 1 point), beginning ( 2 points), in progress ( 3 
points), intermediate (4 points), proficient (5 points), not applicable (0 point)) in three areas: four items of Korean language; five items of mathematics; and one item of overall competence on school performance. This scale measured by web-based questionnaire and teacher in charge of child in school. The Cronbach's alpha reliability coefficient in the current study was.98.

\section{Data collection and analysis}

The data of this study was provided by the Panel Study on Korean Children through their homepage (http://panel.kicce.re.kr/kor/publication/02.jsp). In addition, the construct and correlations and multicollinearity of measurement variables were determined by Pearson correlation coefficients, and the reliability of instruments was confirmed using Cronbach's alpha. Measurement invariance test was conducted to determine if the data of mothers and fathers had homogeneity in the measurement instrument. The maximum likelihood method was used to test the goodness of fit of the model, and confirmatory factor analysis was performed to confirm the validity of latent variables. The evaluation of the goodness of fit of the model was confirmed using $\chi^{2}, \chi^{2} / d f$, RMSEA, SRMR, GFI, AGFI, CFI, NFI or Tucker-Lewis Index (TLI), which are absolute goodness of fit indices. The statistical significance of direct effect, indirect effect, and total effect was determined using bootstrapping. Test of structural model invariance across the groups is an analysis technique that studies path coefficients between measurement models, and analysis for the study was conducted through the process of metric invariance constraints and cross-group equality constraints.

\section{Results}

\section{General characteristics of the subjects}

The average ages of fathers and mothers were $40.1( \pm 3.5)$ years and $37.6( \pm 3.6)$ years, respectively. 89 (37.7\%) fathers were under high school graduates, 51 (21.6\%) college graduates, $96(40.7 \%)$ had bachelors or higher degrees, and 32 (13.5\%). 59 (25.0\%) of the mothers were under high school graduates, $89(37.7 \%)$ college graduates, $88(37.3 \%)$ had bachelors or higher degrees. In terms of occupation, $107(45.3 \%)$ of the fathers were manager or white collar job, while $115(48.7 \%)$ mothers were full-time housewives and 81 (34.3\%) were manager or white collar job. The average household income was KRW 464 million. 140 (59.3\%) of the children were male and 96 (40.7\%) female.

\section{Correlations between measurement variables}

Each measured variable was found to be normally distributed with the absolute values of skewness (0.59 0.79) and kurtosis $(-0.83 \sim 1.91)$ of less than two and four, respectively. All variables had statistically significant correlations at the significance level of 0.05 , and no multicollinearity was found among the variables since the absolute value of correlation coefficients among the variables were no greater than 0.8 (Table 1). 


\section{Measurement invariance test}

Measurement invariance test was conducted to determine if the data of paternal and maternal depression, marital conflict, and parent-child interaction had homogeneity in the measurement instrument, and four competing models were compared. The first model was a default model. For the second model, factor coefficients were restricted; for the third, error covariances were restricted; and for the fourth, factor coefficients and error covariances were restricted. Metric invariance tests, which were conducted to compare the goodness of fit using $\chi^{2}, T L I, C F I$, and RMSEA (indices that are not sensitive to the number of cases), determined that metric invariance was secured.

\section{Hypothesis tests}

To test the effect of parental depression, marital conflict, and parent-child interaction on children's problem behavior and academic performance, the normality of measurement variables was tested. The univariate normality of each measurement variable satisfied normality assumptions with the absolute values of skewness and kurtosis equal to or less than two. However, the assumptions of multivariate normality were not satisfied, since the multivariate kurtosis index was at 16.26 and Critical Ratio (C.R) at 9.26 at significance level of.05. If multivariate normality is not satisfied, a problem of upward skewing of the critical value can occur when parameters are estimated. However, studies have shown that even if multivariate normality is not achieved, if the sample size is 120 or higher, maximum likelihood method can be used to estimate parameters. Based on these reports, models were estimated without transforming the data. The goodness of fit of hypothetical models was evaluated using GFI, AGF, CFI, $\mathrm{NFI}, \mathrm{TLI}, \mathrm{RMSEA}$, and SRMR. If GFI, AGFI, CFI, NFI, TLI are.90 or higher, the goodness of fit of the model is considered to be favorable. For RMSEA and SRMR, if the value is smaller than.05, it is considered an indicator of good fit, while values between.05 and.10 indicate an average fit, and values of.10 or higher indicate low goodness of fit. Hypothetical models of this study were tested using the maximum likelihood method and the results were $\chi^{2}=76.20, \mathrm{df}=30$, RMSEA $=.04$, SRMR $=.05, \mathrm{GFI}=.94, \mathrm{AGFI}=.92, \mathrm{CFI}=.93$, $\mathrm{NFI}=.92$, and $\mathrm{TLI}=.92$, which indicated that the hypothesized data fit the model well, confirming the model. Fourteen out of a total of 18 hypotheses were retained in this study (Table 3 ).

Depression of fathers had an actor effect $(\beta=.46, p<.001)$ and a partner effect $(\beta=.14, p=.018)$ in marital conflict, and depression of mothers had an actor effect $(\beta=.49, p<.001)$ and a partner effect $(\beta=.21, p$ $<.001)$ in marital conflict. Marital conflict of fathers had an actor effect $(\beta=-.27, p<.001)$ and a partner effect $(\beta=-.12, p<.001)$ in parent-child interaction. Marital conflict of mothers had an actor effect $(\beta=$ $-15, p=.047)$ in parent-child interaction. The parent-child interaction of fathers had a direct effect $(\beta=$ $-.16, p<.001)$ on the internalizing problem behavior of children, and mothers' parent-child interaction also had a direct effect $(\beta=-.18, p<.001)$ on the internalizing problem behavior of children. Mothers' parentchild interaction was found to have a direct effect $(\beta=-.16, p=.013)$ on the externalizing behavior problem of children. In addition, mothers' depression was found to have a direct effect on internalizing ( $\beta$ $=.26, p<.001)$ and externalizing behavior problems $(\beta=.30, p<.001)$. Furthermore, parental depression 
and marital conflict were found to have an indirect effect on internalizing and externalizing behavior problems. The internalizing problem behavior $(\beta=-.16, p=.033)$ and externalizing problem behavior $(\beta=$ $-.23, p<.001)$ were found to have a direct effect on children's academic performance, and parental depression, marital conflict, and parent-child interaction were found to have an indirect effect on children's academic performance.

\section{Test of group differences according to household income}

To identify significant differences of path coefficients between groups of more and less than average household incomes of subjects, the critical ratios for the difference between free and constrained models for the 18 paths existing in the research models were determined. The results showed a statistically significant difference in the path in which mothers' depression influences fathers' marital conflict (critical ratio for difference $=2.27, p<.05$ ). The standardized path coefficients from mothers' depression to fathers' marital conflict in the group that earned less than the average income was $\beta=.43(p<.001)$, while that of the group that earned more than the average income was $\beta=.07(p=.059)$.

\section{Discussion}

This study was conducted using asthmatic children and their parents as subjects to determine the actor and partner effects of parental depression, marital conflict, and interaction between children and parents on children's problem behavior and academic performance.

First, the results showed that parental depression has actor and partner effects on marital conflict. This finding is consistent with the results of an earlier study that reported that parental depression affects marital conflict and negatively affects children's physical and emotional development [18]. Depression is a negative emotion with mutual transfer phenomenon, and the transfer phenomenon of depression can be strong and rapid in relationships in which daily stress is experienced in the same space where parents raise children [19]. In particular, because parents of asthmatic children have greater psychological burden of performing many roles as parents since they continuously experience the disease process and growth of children at the same time [4], the transfer phenomenon of parental depression is strong and fast and ultimately becomes the cause of marital conflict and negatively influences the growth and development process, resulting in problem behavior and affecting academic performance of children. Since this study found that maternal depression has a direct influence on children's internalizing and externalizing problem behavior, the effect of maternal depression on children appears to be greater than that of paternal depression. Therefore, it is necessary for health care providers who care for asthmatic children to periodically check parents' depression in the process of managing children's asthma. Medical institutions need to make efforts to provide positive impetus to children's growth and development by helping the husband and wife to maintain a positive relationship. This may be done by including programs that reduce parental depression in the process of managing children's asthma. In addition, the results of the hypothesis test according to household incomes showed that the influence of maternal depression on 
fathers' marital conflict was found to be large in the group that earns less than the average income. The reason is that since asthma is a disease that requires repetitive and long-term treatment, and the financial burden of parents raising children with asthma is relatively greater than that of parents raising normal children [3], the level of depression of mothers in families of lower income is high due to financial burden related to the treatment process of children and it also influences fathers who are responsible for financial activities of the family. Accordingly, it is necessary for the government to prepare a financial support system for families raising asthmatic children.

Second, marital conflict perceived by fathers had actor and partner effects on parent-child interactions, while marital conflict perceived by mothers had an actor effect on parent-child interactions. These results are similar to that of a study on Italian parents and children [20] that marital conflict is a factor that influences parent-child interaction. In light of the emotional security theory, the finding indicates that if the relationship between parents is negative, especially if marital conflict is high, children will perceive their home as an environment that threatens their safety, which impacts parent-child interaction negatively [21]. In particular, since the importance of fathers in families is high in South Korea, marital conflict perceived by fathers appears to negatively influence parent-child interaction perceived by mothers. Accordingly, health care providers need to find methods that can increase interactions between parents and children through the reduction of marital conflict, so that asthmatic children perceive that they are growing and receiving treatments in a safe environment.

Third, parent-child interaction perceived by father was found to affect the internalizing problem behavior of children, and parent-child interaction perceived by mother was seen to affect the internalizing and externalizing problem behavior of children. These findings are similar to findings of a study on Canadian school age children, which reported that interaction between the mother and child affects the problem behavior of children [22]. Since the interaction between fathers and children has a significant role to play in the socialization of children, the parent-child interaction perceived by fathers appears to influence the internalizing problem behavior in children, such as passive and withdrawn behavior, emotional insecurity, and physical symptoms. Mothers, however, appear to affect the internalizing and externalizing problem behavior of children due to their strong emotional interaction with children. Therefore, creating programs and management systems that can maintain positive interaction between parents and children at medical institutions and in society is necessary to prevent asthmatic children's problem behavior.

Fourth, the findings of this study indicate that children's problem behavior influences their academic performance. Such results are similar to the findings of a longitudinal study conducted on children in the U.S. [23], which reported that children's problem behavior is related to academic performance. It appears that children who display problem behavior repeatedly have low academic performance because children's problem behavior negatively influences concentration and memory that are related to learning. Because asthmatic children have limited physical activities and peer relations at school due to their illness, and possibly have a low attendance rate due to repeated treatment process, it is important for them to reduce problem behavior so that they can adjust to school life well. Therefore, it is necessary for home, school, and medical institutions to observe asthmatic children's display of problem behavior with 
interest, and to improve children's adjustment to school by preventing the decline of their academic performance through identification and management of problem behavior early. This study is significant because it prepares basic data for the improvement of academic performance of children with asthma by studying parents' psychological variables, children's problem behavior, and their academic performance at the same time.

\section{Abbreviations}

AGFI: Adjusted goodness-of-fit-index; CFI: comparative fit index; CR: Critical Ratio; df: degrees of freedom; GFI: Goodness of Fit Index; NFI: Normed Fit Index; RMSEA: Root Mean Squared Error of Approximation; SRMR: Standardized Root Mean Square Residual; TLI: Turker-Lewis index

\section{Declarations}

\section{Ethics approval and consent to participate}

This study utilizes secondary data. The 10th year Korea Institute of Child Care and Education survey was conducted after the approval of the Institutional Bioethics Review Board, and this study was also conducted after obtaining approval from the Public Institutional Bioethics Review Board (IRB No. P01201904-23-002) of the Ministry of Health and Welfare. The survey received written informed consent from study participants.

\section{Consent for publication}

Not applicable.

\section{Availability of data and materials}

Not applicable.

\section{Competing interests}

The authors declare that they have no competing interests.

\section{Funding}

Not applicable.

\section{Authors' contributions}

HJW developed a hypothesis, searched the literature, reviewed the relevant articles, analyzed the data, interpreted the findings, and wrote a manuscript. KJM and LH developed the hypothesis, reviewed the relevant article, and wrote the manuscript. All authors have read and approved the manuscript. 
Acknowledgements

Not applicable.

\section{Authors' information}

${ }^{1}$ Nursing Science, Jinju Health College, 51 , Uibyeong-ro, Jinju-si, Gyongsangnam-do ${ }^{2}$ Department of Nursing, Changwon National University, 20 Changwondaehak-ro, Uichang-gu, Changwon, Gyeongsangnam-do, Korea ${ }^{3}$ College of Nursing Science, Kyung Hee University, 24 Kyungheedae-ro, Dongdaemun-gu, Seoul, Korea

\section{References}

[1] Orellano P, Quaranta N, Reynoso J, Balbi B, Vasquez J. Association of outdoor air pollution with the prevalence of asthma in children of Latin America and the Caribbean: a systematic review and metaanalysis. J Asthma. 2018;55:1174-1186.

[2] National Health Insurance Corporation. Preschooler asthma. 2016. https://www.nhisdreams6606.or.kr/menu/retriveMenuSet.xx?menuld = D4000. Accessed 2019 Nov 22.

[3] Everhart RS, Greenlee JL, Winter MA, Fiese BH. Primary and secondary caregiver reports of quality of life in pediatric asthma: are they comparable? Appl Res Qual Life. 2018;13:371-383.

[4] Taminskiene V, Alasevicius T, Valiulis A, Vaitkaitiene E, Stukas R, Hadjipanayis A, et al. Quality of life of the family of children with asthma is not related to asthma severity. Eur J Pediatr. 2019;178:369-376.

[5] Endrighi R, McQuaid EL, Bartlett YK, Clawson AH, Borrelli B. Parental depression is prospectively associated with lower smoking cessation rates and poor child asthma outcomes. Ann Behav Med. 2018;52:195-203.

[6] Brown ES, Gan V, Jeffress J, Mullen-Gingrich K, Khan DA, Wood BL, et al. Psychiatric symptomatology and disorders in caregivers of children with asthma. Pediatrics. 2006;118:e1715-e1720.

[7] Kim-Cohen J, Moffitt TE, Taylor A, Pawlby SJ, Caspi A. Maternal depression and children's antisocial behavior: nature and nurture effects. Arch Gen Psychiatry. 2005;62:173-181.

[8] Turney K. Pathways of disadvantage: Explaining the relationship between maternal depression and children's problem behaviors. Soc Sci Res. 2012;41:1546-1564.

[9] Oh DL, Jerman P, Marques SS, Koita K, Boparai SKP, Harris NB, et al. Systematic review of pediatric health outcomes associated with childhood adversity. BMC Pediatr. 2018;18:83.

[10] Kaugars AS, Klinnert MD, Bender BG. Family influences on pediatric asthma. J Pediatr Psychol. 2004;29:475-491. 
[11] Wolf JM, Miller GE, Chen E. Parent psychological states predict changes in inflammatory markers in children with asthma and healthy children. Brain Behav Immun. 2008;22:433-441.

[12] Lim J, Wood BL, Miller BD, Simmens SJ. Effects of paternal and maternal depressive symptoms on child internalizing symptoms and asthma disease activity: mediation by interparental negativity and parenting. J Fam Psychol. 2011; 25:137-146.

[13] Kenny DA. Models of non-independence in dyadic research. J Soc Pers Relat. 1996;13:279-294.

[14] Kessler RC, Andrews G, Colpe LJ, Hiripi E, Mroczek DK, Normand SL, et al. Short screening scales to monitor population prevalences and trends in non-specific psychological distress. Psychol Med. 2002;32:959-976.

[15] Markman HJ, Stanley SM, Blumberg SL. Fighting for your marriage: positive steps for preventing divorce and preserving a lasting love. San Francisco: Jossey-Bass; 2001

[16] Kim YA, Lee J, Moon SJ, Kim YJ, Oh KJ. Standardization study for the Korean version of the child behavior checklist for ages 1.5-5. Korean J Clin Psychol. 2009;28:117-136.

[17] Rhee UH, Lee JR, Kim MS, Jun HJ. A longitudinal study on early school adjustment and the academic performance of children in low-income families. Korean J Child Stud. 2010;31:65-82.

[18] Hanington L, Heron J, Stein A, Ramchandani P. Parental depression and child outcomes-is marital conflict the missing link? Child Care Health Dev. 2012;38:520-529.

[19] Thompson A, Bolger N. Emotional transmission in couples under stress. J Marriage Fam. 1999;61:38-48.

[20] Camisasca E, Miragoli S, Di Blasio P. Families with distinct levels of marital conflict and child adjustment: which role for maternal and paternal stress? J Child Fam Stud. 2016;25:733-745.

[21] Davies PT, Cummings EM. Marital conflict and child adjustment: an emotional security hypothesis. Psychol. Bull. 1994;116:387-411.

[22] Moss E, Rousseau D, Parent S, St-Laurent D, Saintonge J. Correlates of attachment at school age: maternal reported stress, mother-child interaction, and behavior problems. Child Dev. 1998;69:13901405.

[23] Kremer KP, Flower A, Huang J, Vaughn MG. Behavior problems and children's academic achievement: A test of growth-curve models with gender and racial differences. Child Youth Serv Rev. 2016;67:95-104.

\section{Tables}


Table 1 General Characteristics

\begin{tabular}{|c|c|c|c|}
\hline \multicolumn{2}{|c|}{ Variables } & \multirow{2}{*}{$\begin{array}{r}\mathrm{n} \\
59\end{array}$} & \multirow{2}{*}{$\begin{array}{c}\% \\
25.0\end{array}$} \\
\hline Father's age (yr) & $<36$ & & \\
\hline \multirow{2}{*}{$(\mathrm{M} \pm \mathrm{SD}=40.1 \pm 3.5)$} & $36-40$ & 91 & 38.6 \\
\hline & $40<$ & 86 & 36.4 \\
\hline Mother's age (yr) & $<36$ & 92 & 39.0 \\
\hline \multirow{2}{*}{$(\mathrm{M} \pm \mathrm{SD}=37.6 \pm 3.6)$} & $36-40$ & 93 & 39.4 \\
\hline & $40<$ & 51 & 21.6 \\
\hline \multirow[t]{3}{*}{ Father's education } & Under high school & 89 & 37.7 \\
\hline & College & 51 & 21.6 \\
\hline & Over bachelor's degree & 96 & 40.7 \\
\hline \multirow[t]{3}{*}{ Mother's education } & Under high school & 59 & 25.0 \\
\hline & College & 89 & 37.7 \\
\hline & Over bachelor's degree & 88 & 37.3 \\
\hline \multirow[t]{4}{*}{ Father's occupation } & Manager or white collar job & 107 & 45.3 \\
\hline & Service sector or sales person & 48 & 20.3 \\
\hline & Engineer or machine fabricators & 41 & 17.4 \\
\hline & Others & 40 & 17.0 \\
\hline \multirow[t]{3}{*}{ Mother's occupation } & Manager or white collar job & 81 & 34.3 \\
\hline & House wife & 115 & 48.7 \\
\hline & Others & 40 & 17.0 \\
\hline \multirow{2}{*}{$\begin{array}{l}\text { Family income (million won) } \\
(\mathrm{M} \pm \mathrm{SD}=464.9 \pm 200.8)\end{array}$} & $<400$ & 98 & 41.5 \\
\hline & $\geq 400$ & 138 & 58.5 \\
\hline \multirow[t]{2}{*}{ Sex of child } & Male & 140 & 59.3 \\
\hline & Female & 96 & 40.7 \\
\hline
\end{tabular}

$\mathrm{M}=$ mean, $\mathrm{SD}=$ standard deviation 
Table 2 Correlation of Variables

\begin{tabular}{|c|c|c|c|c|c|c|c|c|c|}
\hline \multicolumn{10}{|c|}{$(\mathrm{N}=263)$} \\
\hline Variables & $\mathrm{X} 1$ & $\mathrm{X} 2$ & X3 & $\mathrm{X} 4$ & $\mathrm{X} 5$ & $\mathrm{X} 6$ & $\mathrm{X} 7$ & $\mathrm{X} 8$ & X9 \\
\hline X1: Depression (Father) & 1 & & & & & & & & \\
\hline X2: Depression (Mother) & $35^{*}$ & 1 & & & & & & & \\
\hline X3: Marital conflict (Father) & $53^{*}$ & $.36^{*}$ & 1 & & & & & & \\
\hline X4: Marital conflict (Mother) & $30^{*}$ & $.54^{*}$ & $.63^{*}$ & 1 & & & & & \\
\hline $\begin{array}{l}\text { X5: Parent-child interaction } \\
\text { (Father) }\end{array}$ & $-.13^{*}$ & $-.10^{*}$ & $-.29^{*}$ & $-.20^{*}$ & - & & & & \\
\hline X6: $\begin{array}{l}\text { Parent-child interaction } \\
\text { (Mother) }\end{array}$ & $-.16^{*}$ & $-.16^{*}$ & $-.19^{*}$ & $-.13^{*}$ & $.24^{*}$ & 1 & & & \\
\hline $\begin{array}{l}\text { X7: Internalizing problem } \\
\text { behavior (Child) }\end{array}$ & $.11^{*}$ & $.17^{*}$ & $.18^{*}$ & $.18^{*}$ & $-.16^{*}$ & $-.13^{*}$ & 1 & & \\
\hline $\begin{array}{l}\text { X8: Externalizing problem } \\
\text { behavior (Child) }\end{array}$ & $.14^{*}$ & $.28^{*}$ & $.12^{*}$ & $.19^{*}$ & $-.15^{*}$ & $-.12^{*}$ & $.22^{*}$ & 1 & \\
\hline $\begin{array}{l}\text { X9: Academic performance of } \\
\text { child }\end{array}$ & $-.18^{*}$ & $-.31^{*}$ & $-.13^{*}$ & $-.27^{*}$ & $.13^{*}$ & $.19^{*}$ & $-.28^{*}$ & $-.69^{*}$ & 1 \\
\hline
\end{tabular}


Table 3 The Test of Measurement Equivalence

\begin{tabular}{|c|c|c|c|c|c|}
\hline Model & $\chi^{2}$ & $\mathrm{df}$ & TLI & CFI & RMSEA \\
\hline \multicolumn{6}{|l|}{ Depression } \\
\hline Model 1 Unconstrained model & 119.00 & 53 & .92 & ,93 & .06 \\
\hline Model 2 Measurement weights constrain & 129.73 & 61 & .92 & .93 & 05 \\
\hline Model 3 Measurement residual constrain & 91.89 & 43 & .91 & .93 & .05 \\
\hline Model 4 Measurement weights and residual constrain & 109.89 & 63 & .91 & 93 & 05 \\
\hline
\end{tabular}

\section{Marital conflict}

Model 1 Unconstrained model

Model 2 Measurement weights constrain

Model 3 Measurement residual constrain

Model 4 Measurement weights and residual constrain $\begin{array}{lllll}269.36 & 103 & .93 & .94 & .04\end{array}$

$\begin{array}{lllll}335.45 & 117 & .89 & .90 & .05\end{array}$

$\begin{array}{lllll}213.50 & 95 & .94 & .95 & .03\end{array}$

$\begin{array}{lllll}273.59 & 109 & .90 & .91 & .05\end{array}$

\section{Parent-child interaction}

Model 1 Unconstrained model

Model 2 Measurement weights constrain

Model 3 Measurement residual constrain

Model 4 Measurement weights and residual constrain $\begin{array}{lllll}352.30 & 169 & .92 & .92 & .03\end{array}$

$\begin{array}{lllll}378.24 & 178 & .89 & .90 & .03\end{array}$

$\begin{array}{lllll}303.72 & 159 & .90 & .92 & .01\end{array}$

$\begin{array}{lllll}340.45 & 179 & .90 & .91 & .04\end{array}$




\begin{tabular}{|c|c|c|c|c|c|c|c|c|c|c|c|c|c|}
\hline \multirow[t]{2}{*}{ Independent variables } & & \multirow[t]{2}{*}{ Dependent variables } & \multirow[t]{2}{*}{$\beta$} & \multirow[t]{2}{*}{$\mathrm{B}$} & \multirow[t]{2}{*}{ S.E } & \multirow[t]{2}{*}{ C.R } & \multirow[t]{2}{*}{$p$} & \multicolumn{2}{|c|}{ Direct effect } & \multicolumn{2}{|c|}{ Indirect effect } & \multicolumn{2}{|c|}{ Total effect } \\
\hline & & & & & & & & $\beta$ & $p$ & $\beta$ & $p$ & $\beta$ & $p$ \\
\hline FD & à & FMC & .46 & .46 & .05 & 8.04 & $<.001$ & .46 & $<.001$ & - & - & .46 & $<.001$ \\
\hline MD & à & FMC & .21 & .20 & .06 & 8.42 & $<.001$ & .21 & $<.001$ & - & - & .21 & $<.001$ \\
\hline FD & à & MMC & .14 & .15 & .06 & 2,37 & .018 & .14 & .018 & - & - & .14 & .018 \\
\hline MD & à & MMC & .49 & .52 & .06 & 8.42 & $<.001$ & .49 & $<.001$ & - & - & .49 & $<.001$ \\
\hline FMC & à & FPCI & -.27 & -.19 & .05 & -3.39 & $<.001$ & -.27 & $<.001$ & - & - & -.27 & $<.001$ \\
\hline MMC & à & FPCI & -.13 & -.12 & .05 & -1.41 & .068 & -.13 & .068 & - & - & -.13 & .068 \\
\hline FD & à & FPCI & - & - & - & - & - & - & - & -.13 & .012 & -.13 & .012 \\
\hline MD & à & FPCI & - & - & - & - & - & - & - & -.17 & .035 & -.17 & .035 \\
\hline FMC & à & MPCI & -.12 & -.19 & .05 & -3.39 & $<.001$ & -.12 & $<.001$ & - & - & -.12 & $<.001$ \\
\hline MMC & à & MPCI & -.15 & -.13 & .05 & -2.60 & .047 & -.15 & .047 & - & - & -.15 & .047 \\
\hline FD & à & MPCI & - & - & - & - & - & - & - & -.15 & .027 & -.15 & .027 \\
\hline MD & à & MPCI & - & - & - & - & - & - & - & -.10 & .049 & -.10 & .049 \\
\hline FPCI & à & IPB & -.16 & .15 & .06 & -2.07 & $<.001$ & -.16 & $<.001$ & - & - & -.16 & $<.001$ \\
\hline MPCI & à & IPB & -.18 & .37 & .06 & -3.21 & $<.001$ & -.18 & $<.001$ & - & - & -.18 & $<.001$ \\
\hline FMC & à & IPB & - & - & - & - & - & - & - & .10 & .042 & .10 & .042 \\
\hline MMC & à & IPB & - & - & - & - & - & - & - & .10 & .007 & .10 & .007 \\
\hline FD & à & IPB & .11 & .07 & .04 & 1.17 & .064 & .11 & .064 & .01 & .002 & .12 & .028 \\
\hline MD & à & IPB & .26 & .61 & .04 & 3.87 & $<.001$ & .26 & $<.001$ & .04 & .008 & .31 & .006 \\
\hline FPCI & à & EIP & -.13 & .36 & .06 & -0.52 & .601 & -.13 & .601 & - & - & -.13 & .601 \\
\hline MPCI & à & EIP & -.16 & .17 & .06 & -2.49 & .013 & -.16 & .013 & - & - & -.16 & .013 \\
\hline FMC & à & EIP & - & - & - & - & - & - & - & .12 & .007 & .12 & .007 \\
\hline MMC & à & EIP & - & - & - & - & - & - & - & .19 & .025 & .19 & .025 \\
\hline FD & à & EIP & .14 & .20 & .04 & 1.52 & .102 & .14 & .102 & .12 & .030 & .26 & .011 \\
\hline MD & à & EIP & .30 & .18 & .04 & 4.62 & $<.001$ & .30 & $<.001$ & .13 & .040 & .43 & .011 \\
\hline FD & à & APC & - & - & - & - & - & - & - & -.16 & .042 & -.16 & .042 \\
\hline MD & à & APC & - & - & - & - & - & - & - & -.18 & .007 & -.18 & .007 \\
\hline FMC & à & APC & - & - & - & - & - & - & - & -.13 & .031 & -.13 & .031 \\
\hline MMC & à & APC & - & - & - & - & - & - & - & -.12 & .038 & -.12 & .038 \\
\hline FPCI & à & APC & - & - & - & - & - & - & - & .18 & .034 & .18 & .034 \\
\hline MPCI & à & APC & - & - & - & - & - & - & - & .24 & .009 & .24 & .009 \\
\hline IPB & à & APC & -.16 & .11 & .01 & 2.01 & .033 & -.16 & .033 & - & - & -.16 & .033 \\
\hline EIP & à & APC & -.23 & .35 & .01 & 3.68 & $<.001$ & -.23 & $<.001$ & - & - & -.23 & $<.001$ \\
\hline
\end{tabular}


Table 5 The Homogeneity Test of Coefficients Applying an Invariance Constraint for each Path

\begin{tabular}{|c|c|c|}
\hline & Model & Critical ratio for difference \\
\hline Model 1 & Depression (Father) -> Marital conflict (Father) & 0.36 \\
\hline Model 2 & Depression (Father) -> Marital conflict (Mother) & -0.63 \\
\hline Model 3 & Depression (Mother)-> Marital conflict (Father) & $2.27 *$ \\
\hline Model 4 & Depression (Mother)-> Marital conflict (Mother) & 0.34 \\
\hline Model 5 & Marital conflict (Father) -> Parent-child interaction (Father) & -0.15 \\
\hline Model 6 & Marital conflict (Father) -> Parent-child interaction (Mother) & 1.03 \\
\hline Model 7 & Marital conflict (Mother) -> Parent-child interaction (Father) & -0.54 \\
\hline Model 8 & Marital conflict (Mother) -> Parent-child interaction (Mother) & 1.47 \\
\hline Model 9 & Parent-child interaction (Father) -> Internalizing problem behavior & -0.19 \\
\hline $\begin{array}{l}\text { Model } \\
10\end{array}$ & Parent-child interaction (Father) -> Externalizing problem behavior & -1.11 \\
\hline $\begin{array}{l}\text { Model } \\
11\end{array}$ & Parent-child interaction (Mother) -> Internalizing problem behavior & -1.41 \\
\hline $\begin{array}{l}\text { Model } \\
12\end{array}$ & Parent-child interaction (Mother) -> Externalizing problem behavior & -1.93 \\
\hline $\begin{array}{l}\text { Model } \\
13\end{array}$ & Depression (Father) -> Internalizing problem behavior (child) & -0.84 \\
\hline $\begin{array}{l}\text { Model } \\
14\end{array}$ & Depression (Father) -> Externalizing problem behavior (child) & -0.30 \\
\hline $\begin{array}{l}\text { Model } \\
15\end{array}$ & Depression (Mother)-> Internalizing problem behavior (child) & -0.40 \\
\hline $\begin{array}{l}\text { Model } \\
16\end{array}$ & Depression (Mother)-> Externalizing problem behavior (child) & -0.51 \\
\hline $\begin{array}{l}\text { Model } \\
17\end{array}$ & Internalizing problem behavior $->$ Academic performance of child & -1.76 \\
\hline $\begin{array}{l}\text { Model } \\
18\end{array}$ & Externalizing problem behavior $->$ Academic performance of child & 0.84 \\
\hline
\end{tabular}

$* \mathrm{p}<.05$ 